\title{
Accounting
}

\section{Influences of the environmental factors on the intention to adopt cloud based accounting information system among SMEs in Jordan}

\section{Malek Hamed Alshirah ${ }^{a *}$, Abdalwali Lutfi ${ }^{\mathrm{b}}$, Ahmad Farhan Alshira'h ${ }^{\mathrm{c}}$, Mohamed Saad ${ }^{\mathrm{b}}$, Nahla Mohamad El Sayed Ibrahim ${ }^{b}$ and Fatihelelah Mohammed Mohammed ${ }^{d}$}

\author{
${ }^{a}$ Accounting Department, Faculty of Economics \& Administrative Science, Al al-Bayt University, Jordan \\ ${ }^{b}$ Department of Accounting, College of Business, King Faisal University, Al-Ahsa, 31982, Saudi Arabia \\ ${ }^{c}$ Faculty of Administrative Sciences and Financial, Department of Accounting, Irbid National University, Jordan
} ${ }^{d}$ King Khalid University, Abha, Saudi Arabia

\section{H R O N I C L E}

Article history:

Received: November 2, 2020

Received in revised format:

November 272020

Accepted: December 21, 2020

Available online:

December 21, 2020

Keywords:

CB-AIS

Institutional Theory

Mimetic pressure

Coercive pressure

Normative Pressure

SMEs

Jordan

\begin{abstract}
A B S T R A C T
The objective of this study is to examine the role of external factors including MP, CP, and NP on the intention to adopt Cloud Based Accounting Information System (CB-AIS). The study proposes a theoretical framework based on institutional theory (INT). The data were collected from small and medium sized enterprise (SMEs) operating in Jordan. A total of 600 questionnaires were distributed to selected SMEs and only 142 were returned and used for the analysis. The empirical data were analyzed using the PLS-SEM modelling. The findings showed that MP, CP, and NP had significant direct associations with the CB-AIS intention to adopt. The results provide important insights to managers, researchers and policymakers to help them understand the importance of CB-AIS adopting to enhance firm performance.
\end{abstract}

\section{Introduction}

Employing a new technology in small and medium-sized enterprises (SMEs) practice offers numerous benefits and functionalities such as reduced costs, better management, effective services, enhanced managerial functionalities and fewer errors (Khassawneh, 2014; Lutfi, 2020; Lutfi, Idris \& Mohamad, 2016; Buntin et al., 2011). A cloud based technology such as Cloud Based Accounting Information System (CB-AIS) that can be defined as "a modern concept processing accounting data with a set of information distribution system and applications in the framework of the concept cloud information without needing for the users to know physical position and system structuring" (Mihalache, 2011:786). CB-AIS solution offers on-demand network access to a shared pool of computing resources, on a pay-per-use basis (Prasad \& Green, 2015). It also enables the opportunity to respond complex and numerous activities and demands by means of integrated online system and, in turn, decreases the amount of labor that is required for accounting department. Compared to the locally managed AIS (traditional system), CB-AIS offers superior opportunities to scale up or down services based on client needs, provides better access to the preferred hardware and software,

* Corresponding author. Tel.: +962795390071

E-mail address: shraamalek@gmail.com (M. H. Alshirah) 
require little capital investment, allow superior cost control (Asatiani et al., 2019), and offers potential for improved collaboration with the supply chain partner (Oliveira et al., 2014).

Existing literature have shown that CB-AIS can provide firms various benefits over the more traditional information systems (ISs), including easy access to affordable ISs that features enhanced the capabilities of data processing, real-time collaboration functionalities, and improved accessibility (Asatiani et al., 2019; Asatiani \& Penttinen, 2019; Oliveira et al., 2014). Adopting of CB-AIS also influences accounting configurations by providing a platform where the client firm and the accounting company can all together work on the data and the process, therefore allowing new ways of organizing the work in an outsourcing association. The potential affordability and flexibility of CB-facilities make these specifically attractive to SMEs that have limited expertise and resources (Rohde, 2004) and, therefore, must be given priority as part of the initiatives to extend business productivity and competitiveness (Chang et al., 2006; Sultan, 2011).

Even though numerous literatures have prevalently looked at the risks as well as benefits of CB-AIS system (e.g., Asatiani et al., 2019; Asatiani \& Penttinen, 2019; Le \& Cao, 2020), to date, few studies have focused to what extent and whether Environmental factors play a significant role in the intention to adopt CB-AIS. Accordingly, the current study asserts that there are various factors that may affect intention to adopt CB-AIS among SMEs. Scholar has framed CB-AIS literature using numerous different contextual adoption frameworks that encompass environmental factors, internal factors and combined organizational viewpoints, more concentration on the internal factors. The current work concentrates on environmental factors influencing the SMEs intention to adopt CB-AIS since there are huge identified gaps between the numbers of research of internal forces and environmental factors. The study subject population is particularly important given today's fluid business environment and the need for works investigating the environmental impacts of aforementioned environmental forces (Kung et al., 2015; Lutfi, 2020). This work seeks to response the following research questions: Whether institutional (environmental) factors influence SMEs owners/managers intention to adopt CB-AIS.?

Inspired by the aforementioned issues, the present study seeks to expand the understanding of CB-AIS with the consideration in classifying the determining factors behind the intention to adopt among SMEs in Jordanian. Through a conceptual framework based on a theoretical model (institutional (INT) theory), the main concern of this work resides in trying to understand factors motivate SMEs to adopt CB-AIS. The contributions of the study lie in numerous aspects. First, the study addresses a gap by concentrating on intention to adopt CB-AIS in Jordan. Secondly, the study incorporates a well-established theory, INT theory. Finally, this study proposes a conceptual framework that assesses the direct influences of environmental factors on the intention to adopt CB-AIS.

The remainder of this paper is structured as follows. Section 2 presents the Theoretical Framework and Hypothesis Development. Third section outlines research methodology. The data analysis is shown in section 4 . Section 5 is dedicated to a discussion of the findings. Section 6 presents the discussion and conclusion, the contributions of the study and provides several insights for future research.

\section{Theoretical Framework and Hypothesis Development}

INT theory (Berger \& Luckmann 1967) has been commonly applied for investigating the diffusion/adoption of organizational technologies (e.g., DiMaggio \& Powell, 1983; Kung et al., 2015; Li \& Wang, 2018; Olivera et al., 2019). INT theory emphasizes that organizational actions or decisions are driven less by effectiveness or efficiency and more by environmental (external) factors as well as the need for legitimacy (Scott \& Christensen,1995). The theory suggests that the organization's decision-making process in a particular industry is beyond rational means and thinking (organizations tend to increase the legitimacy in their decision making through the supports of their institutional environment, and act based on what is foreseeable, justifying their decisions (Heikkilä, 2013; DiMaggio \& Powell, 1983). The INT theory outlines three key dimensions of pressures (institutional pressures) that forcing and influencing the rate of adoption of a technology/innovation that create homogeneity or isomorphism in the organizational processes, structures and strategies, especially those within the surrounding environment and same industry, these dimensions such as coercive pressure (CP) (employed by institution on which organizations depend whether formal forces such as governmental regulations and low or informal pressures such as industry persuasion), mimetic (MP) (pressures emerging from the process of imitating others with the similar industry such as leading firms or competitor's in order to copy with environment uncertainty, and it arise from the organization's environment and forms its behavior), and normative pressures (NP) (arising from social forces on firms and its memberships to adapt to certain norm (DiMaggio \& Powell, 1983; Ke et al., 2009).

Previous empirical studies used the theory of INT in numerous IS/IT technology works, advocate its ability to underline the external factors (drivers) (Tajudeen et al., 2018). INT has been commonly employed to the work of enterprise resource planning (ERP) (Liang et al. 2007), SaaS (Kung et al., 2015), Hospital Information System adoption (Ahmadi et al., 2017), M-Commerce (Li \& Wang, 2018). INT forces were found to be the most influential and representative for the adoption of IS/IT, particularly when it comes in terms of technologies likes CB-AIS (Asatiani et al., 2019). 


\subsection{Mimetic pressure (MP) and intention to adopt $C B-A I S$}

MP, as one of the institutional factors, refers to the degree of ambiguous goals, and misunderstood technologies that may lead firms to capitalize on the experience of competitors by modeling themselves after these successful competitors (DiMaggio \& Powell, 1983; Mitra \& Singhal, 2008). Particularly, the firms will ascribe their competitors' success to their strategic choices and mimic or imitate the behaviors and actions these successful competitors by embracing the same practices and conducts (Li \& Wang, 2018; Zsidisin et al., 2005), to preserve their market share and ensure their survival. Therefore, although imitation is not constantly clearly justifiable by efficiency considerations (Heugens \& Lander, 2009; Ottesen \& Gronhaug, 2002), a firm may still capitulate to mimetic forces to avoid perceived risks and reduce the costs of trialing that are borne by early usersladopters (Kung et al., 2015; Grewal \& Dharwadkar, 2002).

The aforementioned logic can be extended to the context of SMEs with regard to CB-AIS intention to adopt. When SMEs learn how their competitors benefit from CB-AIS, it will perceive mimetic forces to imitate and model these successful firms competitors (Mitra \& Singhal, 2008; Olivera et al., 2019). Given the uncertainties in adopting CB-AIS, exploring the value and outcomes of such system directly is either risky or impossible for firms. To minimize uncertainty or to reduce risks, SMEs may instead succumb to the mimetic forces and be inclined to CB-AIS adoption (Cyert \& March 1963). As acknowledged in the present literature, organizations face greater pressure when it views more and more organizations in the same industry and environment are using innovation successfully and thus feel the need to conform with it as well, to sustain their competitiveness (Chong et al., 2009).

Based on institutional theory, several previous works found out that MP from competitors significantly influences firm's adoption of technologies linnovations. In this regard, Ahmadi et al. (2017) determined out, MP from competitors significantly and positively affects intention to adopt HIS technology among organizations. MP has been extensively measured with perceived success of competitor adaptors and adoption extent among competitors (Teo et al., 2003). Although previous researches on CB-AIS do not explicitly applied INT theory, several prior works indicate that cloud based technologies linnovations adoption in the SMEs context is highly influenced by competitive pressure, which is equivalent to MP exerted by competitors. For instance, Lutfi (2020) in his study of ERP adoption reported that SMEs when see, the other SMEs firms in the same chain adopting the ERP in their operations, the SME feel pressures to adopt ERP system. In addition, Al-ma'aitah, (2017), found that MP has the highest impact on the decision to adopt IS innovations. He believes that emerging countries (competitors) are using the IS to increase and gain more competitiveness, to be perceived favorably and satisfactorily by their customers. Therefore, according to INT theory and earlier studies of IT US adoption with respect to the level of organization, it is highly anticipated that intention to adopt CB-AIS is subject to MP from competitors. Thus, the following hypothesis can be postulated:

\section{H1. There is a positive relationship between MP and intention to adopt CB-AIS.}

\subsection{Coercive pressure (CP) and intention to adopt $C B-A I S$}

CP refers to "result from both formal and informal pressures exerted on organizations by other organizations upon which they are dependent and by cultural expectations in the society within which organizations function" (Powell \& DiMaggio, 1991: p. 67). This kind of pressure is applied when a firm is forced to use certain rules or structures. CP comes from other firms or authorities that have power over the target firm (DiMaggio \& Powell, 1983; Olivera et al., 2019; Teo et al., 2003). CP may also originate from government regulators and industry associations, as well as dominant suppliers or customers. For instance, industry associations might have a large influence on firms. Powerful customers may also require new features that may be more cost effective if executed through CB-AIS. Additionally, firms may be subject to forces from shareholders or parent companies in the absence thereof (Li \& Wang, 2018; Liang et al., 2007). The degree of coercive power from above entities determines specific informal or formal forces on the actions of firm's (Kung et al., 2015; Teo et al., 2003).

Amade et al. (2020) highlighted that CP arise from effects that are originated by structures or legal mandates on which the focal firm is dependent. Considering the adoption IT/IS in the organizational level, CP exerting from government regulatory bodies on an innovative/technology would extensively influence the IT/IS adoption (Al-Okaily, Alqudah, Matar, Lutfi \& Taamneh, 2020b; Olivera et al., 2019; Teo et al., 2003). Lutfi, Idris and Mohamad (2017) examined the role of government policy factors (legislation barriers and government promotion) on the usage and adoption of Accounting Information System (AIS) among SMEs. They found an important predictor in the scope of AIS to be governmental policies. However, a number of the prior works straightly didn't indicate about the CP clarifying why this kind of pressure is exerted from the dependent organizations.

According to INT theory and in line with previous studies of CB-AIS in the context of SMEs as was revised, excluding little, the rest didn't explicitly apply the INT theory, and found the governmental policies as an environmental pressure or driving force significantly and positively related to CB-AIS in SMEs, which is equivalent to CP related to the theory of INT (Alsharari et al., 2020; Haberli et al., 2017). In addition, government set related regulations (policies) that covering diverse set of promotion program or rules to pursue CB-AIS adoption which will cause in the institutionalized adopted CB-AIS (Ahmadi et al., 2017). 
Therefore, it is suggested that the multiplicity of CP from the several sources can significantly influence intention to adopt CBAIS, and vice versa. Accordingly, this study reflects this argument as in the following hypothesis:

\section{H2. There is a positive relationship between $C P$ and intention to adopt $C B-A I S$.}

\subsection{Normative Pressure (NP) and Intention to Adopt CB-AIS}

NP describes the influence of professional standards and the effect of professional communities on a firm (Powell \& DiMaggio, 1991). This kind of pressure captures the ways in which firms are anticipated to conform to professionalism standards and to embrace techniques and systems considered to be legitimate by relevant professional groups. These norms are borne through the training and education of certification and professionals processes accredited by professional bodies. One essential mechanism for inspiring NP is the personnel filtration. Similarly, NP happens when firms comply with their central firm's structures and policies as models which promote structure homogenization.

Wu and Lee (2005) state that NP comes from the scarce of losing the legitimacy. When NP are great, firms tend to adopt technology not based on their evaluations of the potential return and efficiency of the technology, but based on the pressure produced by the sheer number of firms that have already adopted that technology (Abrahamson \& Rosenkopf, 1993). According to Basaglia et al. (2009), the key source of NP force is from relational channels on networks, that is, from customer and supplier. Firms take technology adopted by the customer and the supplier into consideration in their adoption decision making.

Majority of the earlier researches have overlooked the examination of the environmental forces of NP in the intention to adopt CB-AIS within the SMEs context; the few empirical works conducted in this domain have resulted and assured the NP importance on IT/IS adoption within the institutional organizations (Amade et al. 2020; Teo et al., 2003; Liang et al., 2007: Olivera et al. 2019). Ahmadi et al. (2018) examined the acceptance of Hospital Information System (HIS) adoption within an organizational context. They concluded that NP is one of the significant factors affecting the adoption of HIS technology. Martins et al. (2019) highlighted that firms perceive greater tendency to rely upon normative pressures for IT/IS-based systems adoption. In Jordanian SMEs, when CB-AIS is implemented within SMEs, it is necessary to integrate such a system for administrative functions as well as providing means of communication to the relevant departments within firms and also the government ministries. In those departments, variety of users such as accountants and department managers have to involve in using and accepting the applied systems and cooperate with government bodies (Al-Okaily, Lutfi, Alsaad, Taamneh, \& Alsyouf, 2020; Ahmadi et al., 2017). Therefore, the forces are exerted from the users in the professional internal environment. As more SMEs within a given geographical area implement or adopt CB-AIS, they converted to a norm for other firms to operate the system in that area. Therefore, this research proposes that:

\section{H3. There is a positive relationship between NP and intention to adopt $C B-A I S$.}

The hypothesized model or the current research model is presented in the following Fig. 1.

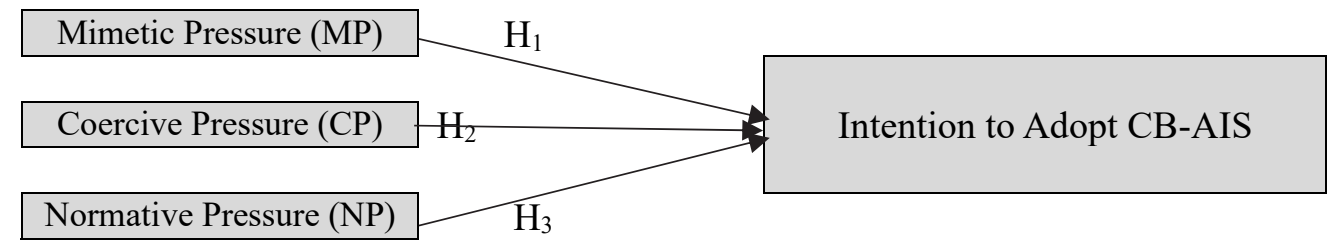

Fig. 1. Research model

\section{Methodology}

The current work is quantitative in nature by exploring the relations among independent and dependent variables. This study considers registered SMEs in Jordan chamber of industry (JCI) as a sampling frame. 17,849 Jordanian SMEs are registered in (JCI, 2017). The sample size in the current study is 377 according to Krejcie and Morgan (1970). In order to avoid low response rate which is common in most studies involving SMEs, there is need to increase the sample size. This will be founded on prior literature that indicated that a non-response rate is at $75 \%$ in the context of business in Jordan (Alshira'h, Alsqour, Lutfi, Alsyouf \& Alshirah, 2020; Alshira'h et al., 2020). Thus, the sample size of the present study increased to be 600 of SMEs. The targeted respondents are owners/managers of SMEs because an owner/manager typically has an extensive understanding about the IS/IT practices of his/her firm and has considerable influence on most of the strategic decisions of his/her firm (Damanpour \& Schneider, 2006). The procedure applied to select a sample was the probability sampling technique because the method is less bias and provides for the most generalizability of findings (Zikmund et al., 2013). Therefore, a systematic random sampling technique was utilized in this study to select 600 of respondents from the list that provided by JCI. The sampling interval for the current study 
was (population/sample size) $17,649 / 600=29$. At a beginning point, the researcher chosen the number 29 and the sampling elements were numbered 29,58, and 87 and so on up to the last sample to be selected. That is, the sampled element number of 600. After around three months, 151 (25.2\%) questionnaires were collected from SMEs. Of them, 9 were incomplete and consequently were removed from the analysis. Therefore, the effective response rate for the present study was (142) $23.7 \%$. The number of responses usable responses that were received met the minimum requirement for analysis utilizing Partial Least SquareStructural Equation Modeling (PLS-SEM), which are 30 responses for a model with four independent variables (Hair et al., 2016). Moreover, Tabachnick and Fidell (2007), in determining the minimum sample, considered the power level desired of significance and number of predictors. Consequently, they suggested the following formula to calculate the size required $(\mathrm{N} \geq[50+8 \mathrm{~m}]$, where $\mathrm{m}=$ number of independent latent variables, and $\mathrm{N}=$ the number of cases). Based on this formula, the minimum required number of cases was 74 , which is less than the number of cases that this study collected (142 cases). Thus, this study had an acceptable number of observations to proceed with the analysis.

\section{Data Analysis}

The current work utilized the PLS-SEM technique for hypothesis testing. PLS-SEM is a multivariate statistical approach that allows for the simultaneous estimation of multiple variables in one single model. This approach also works efficiently when the model is complex involving several latent variables, containing moderating variables and even with relatively lower sample sizes (Alqudah et al., 2019; Al-Okaily et al., 2019; Al-Okaily, Alqudah, Matar, Lutfi \& Taamneh, 2020a; Hair et al, 2016; Reinartz et al., 2009). Based on the aforementioned reasons, the current study employed PLS for testing the hypotheses that were posited, in preference over other techniques, to analyze the data collected. This is because the proposed model contains moderating variables, which increase model complexity. Moreover, the sample size in this study was 192, which is less than the threshold values that are necessary to utilize other techniques. Finally, the current study is explorative in nature in applying the INT and the contingency theories. This combination requires that a path modelling approach be employed because several researchers have suggested that, if a study is prediction-oriented or an extension of an existing theory, then the PLS-SEM approach should be employed (Al-Okaily, Al-Okaily, Shiyyab \& Masadah, 2020; Hair et al., 2014; Henseler et al, 2009; Henseler \& Fassott, 2010; Daoud \& Ibrahim, 2019).

\section{Results and Interpretation}

\subsection{Assessment of measurement model}

Based on Hair et al.'s (2014) recommendation, the evaluation of measurement model is a key step in the PLS-SEM approach, as this evaluation assists in determining if observed indicator constructs are reliable or unreliable. If they prove to be unreliable, this, in turn, restricts moving to evaluate the structural model. Measurement model estimates both reliability and validity of the items as well as constructs. Table 1 reports the relevant indicators that represent the measurement model. The reported data show that all constructs were reliable and valid as all reported scores were more than the thresholds values specified for average variance extracted (AVE), composite reliability (CR) and the Cronbach's alpha (CR) of (0.50, 0.70 and 0.70 respectively) (Hair et al., 2014). All items exhibited acceptable convergent validity because all factors loadings were more than threshold requirements (0.40) on their respective latent construct (Hair et al., 2014). Furthermore, using Fornell-Larcker criterion, the discriminant validity of the variables was established through a comparison of the square roots of AVEs and the inter-construct correlations between constructs.

\section{Table 1}

Relevant Indicators of the Measurement Model

\begin{tabular}{|c|c|c|c|c|c|}
\hline Latent Construct & Item & Item Loading & Cronbach's alpha & Composite Reliability & AVE \\
\hline & & $>0.4$ & $>0.7$ & $>0.7$ & $>0.5$ \\
\hline \multirow[t]{3}{*}{ Intention to Adopt CB-AIS (IACB-AIS) } & IACB-AIS 1 & 0.818 & \multirow[t]{3}{*}{0.844} & \multirow[t]{3}{*}{0.881} & \multirow[t]{3}{*}{0.518} \\
\hline & IACB-AIS 2 & 0.819 & & & \\
\hline & IACB-AIS 3 & 0.757 & & & \\
\hline \multirow[t]{3}{*}{ Coercive Pressure (CP) } & CP1 & 0.816 & \multirow[t]{3}{*}{0.773} & \multirow[t]{3}{*}{0.867} & \multirow[t]{3}{*}{0.686} \\
\hline & $\mathrm{CP} 2$ & 0.823 & & & \\
\hline & CP3 & 0.845 & & & \\
\hline \multirow[t]{3}{*}{ Normative Pressure (NP) } & NP1 & 0.822 & \multirow[t]{3}{*}{0.808} & \multirow[t]{3}{*}{0.872} & \multirow[t]{3}{*}{0.629} \\
\hline & NP2 & 0.813 & & & \\
\hline & NP3 & 0.790 & & & \\
\hline \multirow[t]{3}{*}{ Mimetic Pressure (MP) } & MP1 & 0.770 & \multirow[t]{3}{*}{0.713} & \multirow[t]{3}{*}{0.838} & \multirow[t]{3}{*}{0.633} \\
\hline & MP2 & 0.796 & & & \\
\hline & MP3 & 0.822 & & & \\
\hline
\end{tabular}

As Table 2 shows, all the square roots of AVEs on the diagonal line were greater than the inter-construct correlation, which signifies good discriminant validity. When all the indicators presented are taken into account, the conclusion can be made that the measurement model met the aforementioned requirements at both construct and items level. Therefore, proceeding with an assessment of structural model and testing the hypotheses posited is safe. 
Table 2

Correlations among Latent Constructs (AVE Square Root)

\begin{tabular}{lccc}
\hline & CP & IACB-AIS & MP \\
\hline CP & $\mathbf{0 . 7 1 3}$ & & \\
IACB-AIS & 0.143 & $\mathbf{0 . 7 2 0}$ & \\
MP & 0.088 & 0.168 & $\mathbf{0 . 7 9 6}$ \\
NP & -0.092 & 0.286 & 0.167 \\
\hline
\end{tabular}

Note: The values in bold represent the square root of the AVE.

\subsection{Assessment of the structural model}

Having analyzed the measurement model (outer model), the next step in the PLS-SEM analysis is an assessment of the structural model (inner model). Indeed, the PLS algorithm and bootstrapping test was applied using 5000 resamples to find the level and significance of the path coefficients to test the study hypotheses. Table 3 exhibits the $\beta$-values (standardized path coefficients), tvalues (the critical ratios), and the p-values (in the instances of supported hypotheses) of every single suggested hypothesis. Overall, three hypotheses were sustained at either the $99 \%$ or the $95 \%$ confidence levels. Among them, CP effects on intention to adopt CB-AIS $(\beta=0.214, t=3.483, p<0.000)$ had the strongest effects. Thus, $\mathrm{H} 2$ was supported. MP was significant in determining intention to adopt CB-AIS $(\beta=0.163, \mathrm{t}=2.053, \mathrm{p}<0.040)$. Hence, H1 was supported. With respect to the relationship between $\mathrm{NP}$ and intention to adopt CB-AIS was significant $(\beta=0.154, \mathrm{t}=2.447, \mathrm{p}<0.014)$; therefore, supporting H3.

Table 3

Result of Hypotheses Testing of the Direct Relationship Model

\begin{tabular}{llcccc}
\hline Hypothesis No. & Relationship & Path coefficient & T -Value & P - Value & Decision \\
\hline H1 & MP $\rightarrow$ IACB-AIS & 0.163 & 2.053 & $0.040^{* *}$ & Supported \\
H2 & CP $\rightarrow$ IACB-AIS & 0.214 & 3.483 & $0.000^{* * *}$ & Supported \\
H3 & NP $\rightarrow$ IACB-AIS & 0.154 & 2.447 & $0.014 * *$ & Supported \\
\hline
\end{tabular}

Note: Significant at $* * \mathrm{p}<0.05$, and $* * * \mathrm{p}<0.01$ (one-tailed test). IACB-AIS Intention to Adopt Accounting Information System; MP $=\mathrm{Mimetic}$ Pressure; $\mathrm{CP}=$ Coercive Pressure; $\mathrm{NP}=$ Normative Pressure.

\section{Discussion and Conclusions}

The nomological testing resulted in some interesting findings. The results of this research support hypotheses H1, H2, and H3 as the paths are significant. Authors found that all environmental factors, MP CP, and NP were significant antecedents of intention to adopt CB-AIS. Among these, CP appears to be the most relevant and essential variable influencing the intention to adopt CBAIS, in line with prior works (Li \& Wang, 2018; Swilley et al.,2012). The compulsory natures of CP lead to better environment involvement, which in turn significantly influences intention to adopt CB-AIS. Moreover, developing economies are generally found to rely heavily on government assistance and incentives to accelerate IT/IS adoption (Lutfi et al., 2017; Lutfi, Al-Okaily, Alsyouf, Alsaad \& Taamneh., 2020). Hence, it is appropriate to suppose that the obtaining of valuable and beneficial information from the government would facilitate SMEs to better adopt CB-AIS in support of the essential necessities of a firm.

MP was also found to be significant.MP reflects the action of imitating and copying other structurally comparable firms, including competitors (Teo et al., 2003). To avoid uncertainty and risks, SMEs depend on the competitor's experience, leading to higher participation of the environmental context in CB-AIS intention to adopt. Therefore, it is proposed that SMEs be likely to adopt CB-AIS when they perceived some benefits and advantages could be derived from its application in allocating with greater competitions. SMEs decision-maker would prefer imitating another firm IT/IS choices than adopt recommendations created internally, explicitly, a decision-maker would abandon feedbacks from an internal assessment of different IT/IS options in favor of copying another choices. Similar to other environmental factors, NP was also found to be significant. This finding matches with earlier research that shows the critical significance of NP in the adoption of IT/IS related applications (Li \& Wang, 2018; Swilley et al. 2012). NP is performed by suppliers, governmental agencies, and other bodies that have successfully employed CB-AIS. These bodies by nature share norms, values and information with the firms, leading to better involvement of the environmental situation in intention to adopt CB-AIS. Through NP, SMEs are anticipated to follow to standard of professionalism and to adopt techniques and systems considered greatest practices by related professional bodies. When NP is high, SMEs adopt IT/IS not on their assessments account of the technology potential efficiency, but on account of pressures caused by the number of organizations that have already adopted that technology.

\section{Contributions}

The current study has given an account on the factors affecting intention to adopt CB-AIS among Jordanian SMEs. In spite of extensive research on the adoption of cloud computing, scant study has been related specifically to the intention to adopt CB-AIS 
as well as environmental institutional pressures influences. The results of the current study have several theoretical and practical contributions on the area of CB-AIS and SMEs.

Theoretically, as stated previously, the existing literature review revealed that, although a great deal of attention being concentrated on the adoption of several cloud-computing technologies, very little has been associated specifically to the CB-AIS field. Consequently, the current study offers a validated model for researchers in terms of the factors influences on the intention to adopt CB-AIS. Because of this, the research confirms the usefulness INT theory for studies at the organizational level to the context of CB-AIS, as a guide to realize the intention to adopt CB-AIS.

With respect to practical contributions, SMEs managers and practitioners, industry leaders, and policy-makers who have the desire to understand why Jordanian SMEs lag their larger counterparts in CB-AIS adoption can benefit from the findings of this study. Additionally, the developed and validated model facilitates SME managers in identifying the factors that have greater importance to promoting CB-AIS intention to adopt. The model will help them concentrate on the potential antecedents of intention to adopt CB-AIS on a firm that they may have previously ignored.

From the perspective of a policy maker, this study findings can offer them the capability link the actual adoption and implementation of CB-AIS to organization value creation. Government also can play a more vital role by rendering assistance and creating awareness among SMEs to help them have more access to CB-AIS. Jordan's government needs to enhance awareness in SMEs with respect to the perception of the importance of CB-AIS adoption. Those firms might need to be encouraged to be more responsive to CB-AIS adoption. Thus, one recommendation is to conduct and prepare a comprehensive campaign regarding the importance of CB-AIS to SMEs. This campaign could be in the form of seminars, training courses, publications, and expert visits. On the other hand, governments should also stimulate SMEs to embrace CB-AIS. The benefits of CB-AIS adoption are several, such as cost reductions, quality, productivity and customer service improvements, better decision-making and planning, better resource management, and organizational empowerment.

\section{Limitations and Future Studies}

As always is the case in doing research work, the current research has limitations that should be considered in interpreting the findings. On the other hand, these limitations also provide opportunities for the consideration of future research. First, this study was conducted among manufacturing SMEs in Jordan. Thus, the findings may not be directly generalizable to SMEs in other sectors or in other countries. One possible topic for future study would replicate the research in other sectors and countries. The replication of this research across other sectors and countries might reveal similar or comparable findings and increase the understanding of the adoption issue or if the outcomes are a phenomenon of the Jordanian SMEs setting as a whole. It also would help to validate further the measurement scales, conceptualizations, and generalizability of the results. Second, despite various follow up efforts, the findings of the study were based on a dataset of 142 responses. While this sample size was considered adequate to test the model fit and to proceed with the statistical inferences, future research could verify the study's findings by used a much larger sample that will allow for the usage of covariance-based SEM, which would provide for more robust findings. Likewise, a larger sample size would allow for a richer understanding of the associations between the latent variables and greater confidence in the results. Third, the study utilized cross-sectional data; thus, a causal association between factors could not be ascertained. The utilization of longitudinal data might surmount such a limitation. Fourth, our work focus on intention to adopt CB-AIS rather than on adoption/usage in seeking to improve SMEs performance. According to Janvrin et al. (2008), improving effectiveness/efficiency depends on the adopters/users and not only on the system itself. Therefore, focusing on adoption/usage behaviors is important. Lastly, the current study has overlooked the influence the technological and organizational attributes on the intention to adopt CB-AIS. Thus, it would be interesting for future study to consider these attributes in the organizational context, such as relative advantage, compatibility, firm size, organizational culture, and top management support in order to investigate the interrelationships and causality between factors that are essential to intention to adopt CB-AIS.

\section{References}

Abrahamson, E., \& Rosenkopf, L. (1993). Institutional and competitive bandwagons: Using mathematical modelling as a tool to explore innovation diffusion. The Academy of Management Review 18(3), 487-517.

Ahmadi, H., Nilashi, M., Shahmoradi, L., \& Ibrahim, O. (2017). Hospital Information System adoption: Expert perspectives on an adoption framework for Malaysian public hospitals. Computers in Human Behavior, 67, 161-189.

Ahmadi, H., Nilashi, M., Shahmoradi, L., Ibrahim, O., Sadoughi, F., Alizadeh, M., \& Alizadeh, A. (2018). The moderating effect of hospital size on inter and intra-organizational factors of Hospital Information System adoption. Technological Forecasting and Social Change, 134, 124-149.

Al-ma'aitah, M. (2017). The drivers of ERP cloud computing from an institutional perspective. Journal of Theoretical and Applied Information Technology, 95(19). 
Alsharari, N. M., Al-Shboul, M., \& Alteneiji, S. (2020). Implementation of cloud ERP in the SME: evidence from UAE. Journal of Small Business and Enterprise Development, 27(2), 299-327

Alshira'h, A. F. (2019). The effect of peer influence on sales tax compliance among Jordanian SMEs. International Journal of Academic Research in Business and Social Sciences, 9(3).

Alshira'h, A. F., Al-Shatnawi, H. M., Al-Okaily, M., Lutfi, A., \& Alshirah, M. H. (2020). Do public governance and patriotism matter? Sales tax compliance among small and medium enterprises in developing countries: Jordanian evidence. EuroMed Journal of Business. DOI 10.1108/EMJB-01-2020-0004.

Alshira'h, A. F., Alsqour, M., Lutfi, A., Alsyouf, A., \& Alshirah, M. (2020). A Socio-Economic Model of Sales Tax Compliance. Economies, 8(4), 88.

Alqudah, H., Amran, N. \& Hassan, H. (2019). Factors affecting the internal auditors' effectiveness in the Jordanian public sector: The moderating effect of task complexity. EuroMed Journal of Business, 14(3), 251-273.

Al-Okaily, A., Al-Okaily, M., Shiyyab, F., \& Masadah, W. (2020). Accounting information system effectiveness from an organizational perspective. Management Science Letters, 10(16), 3991-4000.

Al-Okaily, M., Abd Rahman, M. S., \& Ali, A. (2019). Factors Affecting the Acceptance of Mobile Payment Systems in Jordan: The Moderating Role of Trust. Journal of Information System and Technology Management, 4(15), 16-26.

Al-Okaily, M., Lutfi, A., Alsaad, A., Taamneh, A., \& Alsyouf, A. (2020). The determinants of digital payment systems' acceptance under cultural orientation differences: The case of uncertainty avoidance. Technology in Society, 63, 101367.

Al-Okaily, M., Alqudah, H., Matar, A., Lutfi, A., \& Taamneh, A. (2020a). Dataset on the Acceptance of e-learning System among Universities Students' under the COVID-19 Pandemic Conditions. Data in Brief, 32, 1-5, 106176.

Al-Okaily, M., Alqudah, H., Matar, A., Lutfi, A. A. \& Taamneh, A. (2020b). Impact of Covid-19 pandemic on acceptance of elearning system in Jordan: A case of transforming the traditional education systems. Humanities and social Sciences Review, 6(4), 840-851.

Amade, N., Oliveira, T., \& Painho, M. (2020). Understanding the determinants of GIT post-adoption: perspectives from Mozambican institutions. Heliyon, 6(5), e03879.

Asatiani, A., Penttinen, E., (2019). Constructing continuities in virtual work environments: amultiple case study of two firms with differing degrees of virtuality. Information System Journal, 29, 484-513.

Asatiani, A., Apte, U., Penttinen, E., Rönkkö, M., \& Saarinen, T. (2019). Impact of accounting process characteristics on accounting outsourcing-Comparison of users and non-users of cloud-based accounting information systems. International Journal of Accounting Information Systems, 34, 100419.

Basaglia, S., Caporarello, L., Magni, M. and Pennarola, F. (2009). Environmental and organizational drivers influencing the adoption of VoIP. Information Systems and e-Business Management, 7(1), 103-118.

Bocij, P., Chaffey, D., Greasley, A. \& Hickie, S. (2003). Business Information Systems, $2^{\text {nd }}$ ed., Pearson Education, Harlow, UK.

Buntin, M. B., Burke, M. F., Hoaglin, M. C., \& Blumenthal, D. (2011). The benefits of health information technology: a review of the recent literature shows predominantly positive results. Health Affairs, 30(3), 464-471.

Chang, I. C., Hwang, H. G., Yen, D. C., \& Lian, J. W. (2006). Critical factors for adopting PACS in Taiwan: Views of radiology department directors. Decision Support Systems, 42(2), 1042-1053.

Cyert, R. M., \& March, J. G. (1963). A behavioral theory of the firm. Englewood Cliffs, NJ, 2(4), 169-187.

Damanpour, F., \& Schneider, M. (2006). Phases of the adoption of innovation in organizations: effects of environment, organization and top managers. British journal of Management, 17(3), 215-236.

Daoud, L., \& Ibrahim, M. (2019). Antecedents and impacts of electronic procurement usage among Jordanian large firms. Journal of Advanced Research in Business and Management Studies, 14(1), 52-65.

DiMaggio, P.J. and Powell, W.W. (1983). The Iron Cage Revisited: Institutional isomorphism and collective rationality in organizational fields. American Sociological Review 48(2), 147-160.

F. Hair Jr, J., Sarstedt, M., Hopkins, L., \& G. Kuppelwieser, V. (2014). Partial least squares structural equation modeling (PLSSEM) An emerging tool in business research. European Business Review, 26(2), 106-121.

Grewal, R., \& Dharwadkar, R. (2002). The role of the institutional environment in marketing channels. Journal of marketing, 66(3), 82-97.

Haberli Jr, C., Oliveira, T., \& Yanaze, M. (2017). Understanding the determinants of adoption of enterprise resource planning (ERP) technology within the agri-food context: the case of the Midwest of Brazil. International Food and Agribusiness Management Review, 20(1030-2018-023), 729-746.

Hair Jr, J. F., Hult, G. T. M., Ringle, C., \& Sarstedt, M. (2016). A primer on partial least squares structural equation modeling (PLS-SEM). Sage publications.

Henseler, J., \& Fassott, G. (2010). Testing moderating effects in PLS path models: An illustration of available procedures. In Handbook of partial least squares (pp. 713-735). Springer, Berlin, Heidelberg.

Henseler, J., Ringle, C. M., \& Sinkovics, R. R. (2009). The use of partial least squares path modeling in international marketing. In New challenges to international marketing (pp. 277-319). Emerald Group Publishing Limited.

Heugens, P. P., \& Lander, M. W. (2009). Structure! Agency!(and other quarrels): A meta-analysis of institutional theories of organization. Academy of Management Journal, 52(1), 61-85. 
Janvrin, D., Bierstaker, J., \& Lowe, D. J. (2008). An examination of audit information technology use and perceived importance. Accounting Horizons, 22(1), 1-21.

Jordan chamber of Industry [JCI]. Retrieved from: http://www.aci.org.jo/development/en/, (2017).

Khassawneh, A.A.L. (2014). The influence of organizational factors on accounting information systems (AIS) effectiveness: A study of Jordanian SMEs. International Journal of Marketing and Technology, 4(10), 36.

Kung, L., Cegielski, C. G., \& Kung, H. J. (2015). An integrated environmental perspective on software as a service adoption in manufacturing and retail firms. Journal of Information Technology, 30(4), 352-363.

Krejcie, R.V., \& Morgan, D.W. (1970). Determining sample size for research activities. Educational and Psychological Measurement, 30, 607-610.

Le, O., \& Cao, Q. (2020). Examining the technology acceptance model using cloud-based accounting software of Vietnamese enterprises. Management Science Letters, 10(12), 2781-2788.

Li, L., \& Wang, X. (2018). M-Commerce adoption in SMEs of China: the effect of institutional pressures and the mediating role of top management. Journal of Electronic Commerce in Organizations (JECO), 16(2), 48-63.

Liang, F., Mukherjee, S., \& West, M. (2007). The use of unlabeled data in predictive modeling. Statistical Science, 22(2), 189205.

Liang, H., Saraf, N., Hu, Q., \& Xue, Y. (2007). Assimilation of enterprise systems: the effect of institutional pressures and the mediating role of top management. MIS quarterly, 31(1), 59-87.

Lutfi, A. (2020). Investigating the moderating effect of Environment Uncertainty on the relationship between institutional factors and ERP adoption among Jordanian SMEs. Journal of Open Innovation: Technology, Market, and Complexity, 6(3), 91.

Lutfi, A. A., Idris, K. M., \& Mohamad, R. (2017). AIS usage factors and impact among Jordanian SMEs: The moderating effect of environmental uncertainty. Journal of Advanced Research in Business and Management Studies, 6(1), 24-38.

Lutfi, A. A., Idris, K. M., \& Mohamad, R. (2016). The influence of technological, organizational and environmental factors on accounting information system usage among Jordanian small and medium-sized enterprises. International Journal of Economics and Financial Issues, 6(7S), 240-248.

Lutfi, A., Al-Okaily, M., Alsyouf, A., Alsaad, A., Taamneh, A. (2020). The Impact of AIS Usage on AIS Effectiveness among Jordanian SMEs: A Multi Group Analysis of the Role of Firm Size. Global Business Review, 1-19.

Martins, R., Oliveira, T., Thomas, M., \& Tomás, S. (2019). Firms' continuance intention on SaaS use-an empirical study. Information Technology \& People, 32(1), 189-216.

Mihalache, AS. (2011), "Cloud Accounting”. Ovidius University Annals, Economic Sciences Series, 11(2), 782-787.

Mitra, S., \& Singhal, V. (2008). Supply chain integration and shareholder value: Evidence from consortium based industry exchanges. Journal of Operations Management, 26(1), 96-114.

Oliveira, T., Martins, R., Sarker, S., Thomas, M., \& Popovič, A. (2019). Understanding SaaS adoption: The moderating impact of the environment context. International Journal of Information Management, 49, 1-12.

Oliveira, T., Thomas, M., Espadanal, M., (2014). Assessing the determinants of cloud computing adoption: an analysis of the manufacturing and services sectors. Information Management, 55, 497-510.

Oredo, J. O., Njihia, J., \& Iraki, X. N. (2019). Adoption of cloud computing by firms in Kenya: The role of institutional Pressures. The African Journal of Information Systems, 11(3), 1.

Ottesen, G. G., \& Grønhaug, K. (2002). Market orientation and uncertain supply in upstream markets: an exploratory study. European Journal of Purchasing \& Supply Management, 8(4), 209-219.

Prasad, A., \& Green, P. (2015). Governing cloud computing services: Reconsideration of IT governance structures. International Journal of Accounting Information Systems, 19, 45-58.

Reinartz, W., Haenlein, M., \& Henseler, J. (2009). An empirical comparison of the efficacy of covariance-based and variancebased SEM. International Journal of Research in Marketing, 26(4), 332-344.

Rohde, F. H. (2004). IS/IT outsourcing practices of small-and medium-sized manufacturers. International Journal of Accounting Information Systems, 5(4), 429-451.

Sultan, N. A. (2011). Reaching for the "cloud": How SMEs can manage. International Journal of Information Management, 31(3), 272-278.

Swilley, E., Hofacker, C. F., \& Lamont, B. T. (2012). The evolution from e-commerce to m-commerce: pressures, firm capabilities and competitive advantage in strategic decision making. International Journal of E-Business Research (IJEBR), 8(1), 1-16.

Tabachnick, B.G., \& Fidell, L.S. (2007). Using Multivariate Statistics (5th Ed.). Boston: Pearson Education Inc.

Teo, H.H., Wei, K.K. and Benbasat, I. (2003). Predicting Intention to Adopt Interorganizational Linkages: An institutional perspective, MIS Quarterly 27(1), 19-49.

Wu, W.W. (2011). Mining significant factors affecting the adoption of SaaS using the rough set approach. The Journal of Systems and Software, 84(3), 435-441.

Wu, F., \& Lee, Y. (2005). Determinants of e-Communication Adoption: The internal push versus external pull factor. Marketing Theory, 5(1), 7-31.

Yee-Loong Chong, A., Ooi, K. B., Lin, B., \& Yi Tang, S. (2009). Influence of interorganizational relationships on SMEs'ebusiness adoption. Internet Research, 19(3), 313-331. 
Zikmund, W.G., Babin, B.J., Carr, J.C., \& Griffin, M. (2013). Business research methods. (Ninth edition). Cengage Learning, Canada.

Zsidisin, G., Melnyk, S. and Ragatz, G. (2005). An institutional theory perspective of business continuity planning for purchasing \& supply management. International Journal of Production Research, 43(16), 3401-20.

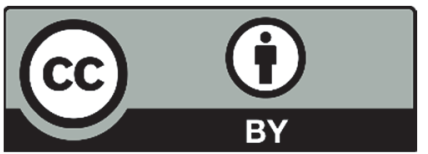

(C) 2021 by the authors; licensee Growing Science, Canada. This is an open access article distributed under the terms and conditions of the Creative Commons Attribution (CC-BY) license (http://creativecommons.org/licenses/by/4.0/). 